\title{
ALGUNAS CONSIDERACIONES SOBRE LAS COMISIONES INVESTIGADORAS PARLAMENTARIAS
}

Francisco José Eguiguren Praeli

El art ículo $180^{\circ}$ de la Constitución Peruana de 1979 establece la potestad parlamentaria de nombrar comisiones investigadoras y el marco general de su competencia y atribuciones. Esta norma presenta hasta tres importantes novedades con respecto a lo dispuesto por el artículo $119^{\circ}$ de la Carta de 1933: En primer lugar, se faculta a que las comisiones investigadoras puedan ser nombradas tanto por el Congreso como separadamente por cualquiera de ambas Cámaras, ampliando así esta atribución que la Carta anterior sólo conced ía a las Cámaras de Diputados y Senadores. En segundo lugar, la Constitución vigente impone carácter obligatorio a la comparecencia ante el requerimiento de la comisión, haciéndole aplicables los apremios propios del procedimiento judicial para lograr su efectivo cumplimiento, superando la omisión de la antigua norma que se limitaba a enunciar la obligación de suministrarle la información o documentos solicitados, pero sin habilitar expresamente medio coercitivo alguno. $Y$ en tercer lugar, a diferencia de la anterior norma que aparentemente restringía la competencia investigatoria de la comisión tan sólo a las autoridades administrativas y judiciales, la nueva norma permite extender la competencia de la comisión, para fines de investigación, sobre cualquier autoridad, funcionario o persona particular.

Es de observar, sin embargo, que debido al insuficiente afianzamiento de nuestra institucionalidad constitucional y a su efecto en el escaso desarrollo de las instituciones parlamentarias, existen innumerables dudas e interrogantes acerca de los alcances de la competencia y atribuciones concretas de las comisiones investigadoras, especialmente en relación a aspectos tales como la extensión de los apremios y medios coercitivos que pueden utilizar o a su situación frente a asuntos que simultáneamente vienen siendo objeto de investigación ante el Poder Judicial y las autoridades judiciales. En verdad es muy poco lo que se ha avanzado en nuestro pa is 
in el tratamiento y esclarecimiento de estos temas, pese a su trascendental importancia, a consecuencia de la incipiente elaboración de la doctrina constitucional y a la falta de trabajos de sistematización y difusión de nuestra experiencia parlamentaria. Es atendiendo a estas consideraciones, que se ofrecen a continuación algunas reflexiones y planteamientos -. ciertamente preliminares - en torno a estos controvertidos problemas.

\section{COVSIDERACIONES GENERALES}

\subsection{Concepto y naturaleza}

Las comisiones parlamentarias, a decir de César Romero (1) son desprendimientos del propio cuerpo legislativo, que en virtud del privilegio colectivo de toda asamblea de base popular de darse su reglamento o dictar las normas de su funcionamiento, son designadas ya sea de modo permanente o transitorio, o para misiones determinadas, con el objeto de que asesoren al Congreso o a sus respectivas Cámaras mediante tareas especializadas, fiscalicen funciones administrativas de la rama parlamentaria o investiguen hechos y circunstancias que el cuerpo ha considerado necesario para adoptar medidas ya en el plano de la responsabilidad de los funcionarios o en el ámbito de la legislación. De las tareas precedentemente recordadas, deriva la clasificación de las comisiones parlamentarias en permanentes, transitorias e investigadoras.

Las comisiones parlamentarias se enmarcan dentro de los privilegios propios de este Poder del Estado, encontrando su razón de ser y justificación en las facultades y prerrogativas fundamentales que la Constitución le confiere al Parlamento atendiendo a su calidad de máxima asamblea deliberante representativa de la voluntad popular, y para el adecuado desempeño de las funciones legislativas. fiscalizadoras y de control político que le son inherentes.

Las comisiones investigadoras que designan cada una de las Cámaras o el Congreso en su conjunto, son un privilegio o prerrogativa esencial que la doctrina y el constitucionalismo comparado reconocen como propias y naturales del Poder Legislativo para el

(1) ROMERO, César Enrique: en, Enciclopedia Juridica OMEBA; Comi. siones Parlamentarias, T. III, pag. 371 
desempeño de sus funciones y el cabal cumplimiento de éstas. Como acertadamente señala Linares Quintana (2) el derecho de intormación-que comprende el de investigar-- es inherente a todo poder que delibera, que vota y que decide y que a ese fin tiene la necesidad de conocer la verdad. De acuerdo con su sentido gramatical. imestigar, del lat ín investigare, significa hacer diligencias para descubrir una cosa; a su vez. descubrir, entre otras acepciones, comporta hallar lo que estaba ignorado o escondido, registrar o alcanzar a ver, venir en conocimiento de una cosa que se ignora.

Las comisiones investigadoras encuentran su origen en el desarrollo de esta práctica desde el parlamento británico y su ulterior continuidad en la experiencia de las colonias inglesas de norteanérica antes de la independencia de los Estados Unidos. De allí que aunque en el texto de la Constitución de los Estados Unidos no aparece mención expresal a la existencia de estas comisiones. ya kesde 1792 la Cámara de Representantes conformó comisiones investigadoras, reafirmando desde entonces el Congreso y la Suprema Corte el pleno fundamento constitucional de dicha atribución del Poder Legislativo. Similar eriterio se siguió en Argentina, cuya Constitución tampoco contempla expresamente las comisiones investigadoras parlamentarias. acogiénctose el criterio de que se trata de facultades o poderes implicitos contenidos en la carta constitucional y en la esencia de la labor y prerrogativas del Congreso y sus Cámaras.

Fs por ello que desde entonces se asume que las comisiones investigadoras, por ser una delegación de las propias cámaras congresales. gozan de las mismas prerrogativas del Poder Legislativo y sus miembros, tanto las que derivan de la Constitución o de los Reglamentos parlamentarios, como las que fluyen de la resolución del cuerpo parlamentario que les da nacimiento, asi como también las lacultades implicitas que nacen de las delicadas funciones asignadas y del objetivo parlamentario que se ha propuesto con su creación.

(2) LINARES QUINTANA, Segundo: "Límites constitucionales de la facultad de investigar del Congreso'; en, Revista Jurídica Argentina LA LEY, 1984-D, pag. 1025. 
Si bien existe consenso en la competencia parlamentaria para conformar comisiones investigadoras, suscita más bien amplia discusión el alcance de las atribuciones y limites que regulan su actuación y funcionamiento. En el caso norteamericano, por ejemplo, ante la ausencia de normas sobre la materia, tales aspectos han ido estableciéndose mediante las decisiones del Congreso y de la $\mathrm{Su}$ prema Corte, especialmente en lo referente a los poderes coercitivos que asisten a dichas comisiones para ejercer sus funciones y lograr los objetivos de la investigación.

Cabe mencionar los conceptos expuestos por el juez Van Devanter, en el caso Mc. Grain vs. Daugherty (1927) criterio posteriormente asumido en la práctica norteamericana, cuando al referir los fundamentos de la investigación parlamentaria y los medios que pueden utilizar las comisiones anota que ". . la experiencia ha enseñado que los meros pedidos de información a menudo son inútiles y asimismo que la información que es voluntariamente suministrada no siempre es precisa o completa; por ello algunos medios de compulsión son esenciales para obtener lo que se necesita. Todo esto era asi antes y al tiempo en que la Constitución fue estructurada y puesta en vigor" (3). Tales medios coercitivos consisten en la comparecencia obligatoria ante el requerimiento de la comisión, sea para prestar testimonio o responder preguntas, para exhibir o entregar documentos o para proporcionar informes; existiendo apremios que, de ser el caso, pueden ser legítimamente empleados por la comisión para conseguir el cumplimiento forzoso e irresistible de su mandato por parte de las personas incursas en el proceso investigatorio.

Es importante tener presente antiguos precedentes norteamericanos, como cuando en el caso Kilbourn vs. Thompson (1881) no obstante que se ventilaba ante los tribunales, la Cámara de Representantes conformó una comisión investigadora dotándola de atribuciones para forzar a algunas personas a rendir testimonio ante ella y para incautar documentos. Igualmente en el caso Sinclair vs. USA (1929) la Corte reafirmó la competencia del Senado para

(a) Citado por LOZANO Luis: "Facultades de investigación del Congreso". Rev. Jur. Argontina LA LEY. 1984-D, pag. 1013. 
nombrar comisiones investigadoras sobre un asunto que se encuentra en juicio, y para forzar a prestar testimonio a una persona que se resist ía a hacerlo alegando la existencia del proceso judicial, sosteniendo el Supremo Tribunal que ". . la facultad de exigir información en ayuda de una atribución constitucional no se ve reducida o limitada por el hecho de que la información buscada pueda también ser útil en el pleito".

De lo expuesto se puede concluir que para el sistema norteamericano es admisible (en muchos casos) que el Congreso y el Poder Judicial puedan eventualmente hacer converger sus investigaciones sobre un mismo asunto, siempre y cuando la finalidad de la investigación de cada uno de dichos órganos esté en el marco de su competencia. No basta pues argumentar que la justicia se está ocupando de un caso para que el Congreso deba cerrar los ojos ante el hecho, ni viceversa (4).

En el caso argentino, la Cámara de Diputados estableció en una resolución de 1915 que "es facultad suya inherente a su carácter representativo y necesaria para el desempeño de sus funciones, la designación de comisiones investigadoras en su seno, para fines de iniciativa parlamentaria, de reforma de la legislación o de responsabilidad de funcionarios". Posteriormente, en 1917, declaró que ". . le corresponde también determinar la forma en que, en cada caso y a los fines del mejor desempeño de la función legislativa, considera que le deben ser suministrados los informes y explicaciones que solicita". Y en 1918 reafirmó ese derecho, agregando que la Cámara por sí o por sus comisiones investigadoras puede requerir el testimonio de personas y la exhibición de documentos que tenga o que puedan tener relación inmediata con el objeto de la investigación (5).

Inclusive cuando en 1934 el Senado Argentino dispuso la investigación del comercio de carnes, confirió a la comisión poderes para “. . .requerir el testimonio de personas y la exhibición de libros, papeles o documentos que tengan o pudieran tener relación

(4) LOZANO Luis: op. cit. pág. 1016.

(5) RAMELLA Pablo: "Comisiones investigadoras"; en Rev. LA LEY, 1984 D, pags. 962-963. 
inmediata con los fines de la investigación y el interés público que clla contempla". Además dicha comisión realizó allanamientos de domicilios y de buques e incautación de documentos, sin solicitar e) auxilio de la fuerza pública ni autorización del Poder Judicial, estableciéndose el precedente que la verificación de estos actos, que indudablemente conllevan restricciones a derechos ciudadanos, resultaba admisible si con ello se lograba aceeder a la verdad y a los fines de la investigación, evitando que éstas se vean frustradas o burladas.

Como es natural imaginar, reviste especial trascendencia a la par de suscitar controversias el reconocimiento de este tipo de atribuciones, poderes coercitivos y apremios a las comisiones investigadoras parlamentarias, así como la determinación de los límites impuestos a los mismos. Se ha señalado que en el proceso judicial existen mecanismos compulsivos que, aunque limitan aparentemente derechos de las personas afectadas, están destinados a la búsqueda de la verdad y el esclarecimiento de hechos o pruebas. takes como concurrencia forzada a rendir testimonios. detención a quien desacate tal mandato judicial, respuesta obligatoria a los interrogatorios, prohibición de salida del pa ís a quienes están procesados, exhibición, incautación o secuestro de documentos, etc. Del mismo modo, se sostiene que la investigación que realizan las comisiones parlamentarias requieren para su eficacia de similares apremios y poderes coercitivos.

Algunas de estas atribuciones, como la comparecencia forzosa de quien es citado a declarar o a prestar testimonio, o la facultad de requerir la entrega o exhibición de documentos y similares ("power to send for papers and records") ya han alcanzado pleno reconocimiento como potestades propias de las comisiones investigadoras parlamentarias. Otras, como la competencia para ordenar o efectuar arresto de personas, secuestro de documentos o allanamiento de domicilios. cuentan con algunos precedentes y han adquirido cierta aceptación en normas o prácticas vinculadas a la labor investigativa del parlamento. De allí que en pa íses como Espana algunos de estos poderes coercitivos y apremios constan en leyes orgánicas y Reglamentos del Congreso o las Cámaras. y que en Argentina se estén proponiendo reformas constitucionales y legislativas para incorporarlos clara, plena y estensamente. 
La Constitución Peruana de 1979 contempla expresamente. en su artículo $180^{\circ}$ la existencia de las comisiones parlamentarias de investigación, disponiendo que "El Congreso y' cada Cámara pueden nombrar Comisiones de Investigación sobre cualquier asunto de interés público. Es obligatorio comparecer al requerimiento de dichas Comisiones, bajo los mismos apremios que se observan en el procedimiento judicial'.

Si bien dicha norma explicita releva de la necesidad de abundar en el evidente sustento constitucional de las comisiones investigadoras, cabe afirmar que inclusive su existencia podia desprenderse implícitamente de la aplicación del inciso $2^{\circ}$ del art $186^{\circ} \mathrm{de}$ la Carta, que establece que "Son atribuciones del Congreso: Velar por el respeto de la Constitución y" de las leyes, y' disponer lo conveniente para hacer efectiva la responsabilidad de los infractores".

Del análisis e interpretación de dichas normas, podría afirmarse que el marco constitucional de las comisiones investigadoras parlamentarias tiene la características siguientes:

a) Las comisiones investigadoras pueden ser de diputados, de senadores o bicamerales, ya sea que su nombramiento provenga respectivamente de las Cámaras de Diputados, de Scnadores o del Congreso. Esta es una importante innovación con respecto a la Constitución de 1933, cuyo art. $119^{\circ}$ sólo ten ía previsto el nombramiento de comisiones investigadoras por cada una de las cámaras.

b) Las comisiones investigadoras surgen necesariamente de un acuerdo aprobado por la mayor ía de los miembros de la cámara respectiva o del Congreso en su conjunto, por lo que su legitimidad y representatividad son incuestionables, al igual que la autoridad y poderes que les asisten. Así difieren de los casos de pedidos de interpelación o censura a los ministros, que pueden admitirse con la aprobación de una minoría.

c) Los casos que pueden ser materia de investigación, quedan sometidos a la decisión autónoma y discrecional del Congreso o las 
Cámaras. Y aunque la Constitución establece que el asunto a investigar debe ser de interés público, la apreciación y calificación de tal carácter compete a los órganos del propio Poder legislativo. Es de suponer que el acuerdo parlamentario que conforma la comisión, deberá cuidar de expresar la trascendencia e interés del asunto a investigar, los objetivos que se persiguen con dicha investigación $y$, eventualmente, los encargos concretos o facultades expresas que se confieren a la comisión.

d) La labor y la finalidad de la comisión investigadora deberán estar orientadas a obtener la información que las Cámaras o el Congreso requieren para tomar conocimiento, formarse opinión y adoptar decisiones en relación a los asuntos objeto de investigación. En tal sentido, será esencial determinar mediante este procedimiento la existencia de posibles casos de transgresiones a la Constitución o las leyes, así como identificar a los infractores y las eventuales responsabilidades en que pudieran estar incursos funcionarios públicos, autoridades o personas particulares. Del resultado de la investigación pueden derivarse - según los casos-acciones de responsabilidad política (interpelación o censura de ministros) de responsabilidad penal o constitucional de altos funcionarios (susceptibles de acusación constitucional y antejuicio ante el parlamento) o de responsabilidad penal común de personas que pueden ser denunciadas ante el Ministerio Público para que éste resuelva sobre la procedencia de dicha acción ante el Poder Judicial.

e) Las personas citadas a comparecer ante la comisión, deberán concurrir necesariamente ante ella, pudiendo ésta -en caso de resistencia o incumplimiento - hacer uso de apremios similares a los utilizados en procesos judiciales, es decir, haciendo que el obligado concurra por la fuerza, conducido por la autoridad policial. Evidentemente se trata de un mecanismo coercitivo indispensable, que busca dar mayor eficacia a la función investigadora de la comisión y al cumplimiento de sus mandatos o decisiones.

Sin embargo, a pesar de la aparente claridad de esta normatividad constitucional, existen diversos aspectos polémicos en torno a los alcances de la competencia, atribuciones y actuación de las comisiones investigadoras. Muchos de estos problemas se han ido evidenciando en el propio funcionamiento de las comisiones y ante las necesidades concretas que éstas afrontan para el cumplimiento 
de su labor, dejando al descubierto las insuficiencias y omisiones de la legislación y la reglamentación parlamentaria vigente en esta materia. Ello hace aconsejable que en la tarea parlamentaria se vayan estableciendo las precisiones que permitan dilucidar muchas de estas interrogantes y controversias, tanto a través de reformas legislativas y en los Reglamentos del Congreso y las Cámaras, como de la reflexión y sistematización en torno a experiencias y decisiones que sirvan de precedentes, para contribuir al mejor desarrollo de esta institución esencial para las funciones de fiscalización y control que son inherentes al Parlamento.

3. ALGUNOS PROBLEMAS DERIVADOS DEL FUNCIONAMIENTO DE LAS COMISIONES INVESTIGADORAS PARLAMENTARIAS EN EL PERU

\subsection{Comisiones investigadoras y comisiones de acusación consti- tucional}

La Constitución Peruana de 1979 dispone en su art. 180 que las comisiones investigadoras parlamentarias pueden ser nombradas por el Congreso o por cada una de las Cámaras. Por ello debe quedar muy en claro que las comisiones investigadoras nombradas por el Congreso, gozan de la misma competencia y atribuciones que asisten a las que habitualmente conforman, autónoma y separadamente, las Cámaras de Diputados o Senadores. Incluso cabría afirmar que una comisión investigadora del Congreso posee una autoridad moral aún mayor - si cabe la expresión - toda vez que surge de la voluntad mayoritaria del conjunto de representantes de ambas cámaras parlamentarias.

Es muy posible que del dictamen final de una comisión investigadora se desprendan responsabilidades penales o constitucionales de altos funcionarios, susceptibles de hacerlos pasibles de ulterior acusación constitucional por la Cámara de Diputados, de acuerdo al procedimiento especial del antejuicio previsto en los arts. $183^{\circ}$ y $184^{\circ}$ de la Constitución. Ello no puede llevar a sostener (como algunos han intentado) que las comisiones investigadioras del Congreso o del Senado adolescen de menor competencia frente a las de Diputados, aduciendo que sólo estas últimas poseen atribuciones acusatorias. En realidad, no cabe confundir las competencias y atribuciones de una comisión investigadora (sea de Senado- 
res, de Diputados o del Congreso ) con las que corresponden a una comisión especial de acusación constitucional nombrada por la Cámara de Diputados exprofesamente para tal efecto. Se trata de dos procedimientos distintos, claramente diferenciados e independientes entre sí.

Ninguna comisión investigadora es realmente acusadora, pues su dictamen final no acusa sino que formula conclusiones y recomendaciones que. en el caso de referirse a posibles responsabilidades penales o constitucionales de altos funcionarios, pueden o no ser acogidas ulteriormente por Diputados. Sólo si dicha Cámara comparte el parecer de que cabe iniciar un procedimiento de acusación constitucional, conformará una comisión de diputados para que emprenda esta tarea. Es por ello que también el Senado y el Congreso poseen competencia para nombrar comisiones investigadoras, pese a que ambos carecen de facultad para formular directamente una acusación constitucional.

Conviene al respecto recordar innumerables precedentes, como el de la comisión investigadora del Congreso en el caso de la Irrigadora Chimbote (nombrada el 23-1 1-82) o las comisiones investigadoras del Senado en los casos SVIRLS (11-9-80), inversiones en el Departamento de Ancash por CRYRZA, ORDEZA y ORDENOR (17-9-80), irregularidades cometidas en las obras de aplicación urbana en Reducto 3 (30-4-81). Banco Ambrosiano Andino, o las de Accomarca y Pucayaccu, por citar algunos. Todas ellas fueron nombradas presuponiendo la existencia de eventuales responsabilidades que podrían luego dar lugar a procedimicntos de acusación constitucional, criterio reafirmado en agosto del 86 al nombrarse una comisión del Congreso para investigar los luctuosos sucesos acaecidos en junio de ese año, a raíz del amotinamiento de internos inculpados y procesados por terrorismo recluidos en tres penales de Lima y Callao.

Finalmente, en cuanto a la naturaleza y efectos de las conclusiones a que puede llegar el dictamen final de una comisión investigadora, ya se ha dicho que éstas constituyen recomendaciones y sugerencias que ilustran y colaboran en las decisiones que sobre el asunto puedan adoptar libremente el Congreso o las Cámaras. Es también importante lo dispuesto en el segundo párrafo del art. $79^{\circ}$ del Reglamento Interior del Senado, cuando señala que copias del 
informe final de la comisión serán remitidas a los Ministros de Estado que corresponda y, si hay presunción de delitos, al Ministerio Público, a fin de que resuelvan lo pertinente. Con igual finalidad es perfectamente posible y conveniente remitir una copia a la Cámara de Diputados, a efecto de que a su interior pueda formularse, de ser el caso, alguna iniciativa de acusación constitucional contra los responsables de infracciones contra la Constitución o de delitos cometidos en el ejercicio de funciones públicas.

\subsection{Comparecencia ante la comision y apremios aplicables}

Otro aspecto fundamental del art. $180^{\circ}$ de la Constitución, es que reafirma la autoridad que asiste a las comisiones investigadoras parlamentarias para lograr la participación y concurrencia --si es necesario de manera forzosa- de las personas que son citadas o a quienes se solicita alguna información para el desarrollo de la investigación. Dicha norma dispone expresamente que ". . es obligatorio comparecer al requerimiento de dichas Comisiones, bajo los mismos apremios que se observan en el procedimiento judicial".

$Y$ tales medios coercitivos (conforme manda nuestra Constitución) consisten en la atribución para exigir y conseguir la comparecencia obligatoria ante la comisión de quien es citado a prestar declaraciones y absolver preguntas, rendir testimonio, suministrar informes o documentos, en relación a hechos y asuntos vinculados a la investigación. En caso de resistencia o incumplimiento a sus mandatos, la comisión hará uso de los apremios previstos en los procedimientos judiciales (tales como los consignados en los arts. $184^{\circ}$ a $201^{\circ}$ del Código de Procedimientos Civiles) para que se produzca la detención del renuente o rebelde y su conducción por la fuerza pública ante la comisión a fin de dar cumplimiento a sus requerimientos.

Aunque este apremio de detención parece no haber sido utilizado hasta el momento (desde la vigencia de la Carta de 1979) existe consenso en su procedencia y aplicación para exigir que la persona citada cumpla con comparecer ante la comisión a prestar testimonio o declaraciones, o a hacer entrega de informes y rocumentos. Cabe sin embargo preguntarse si el mandato de detención podría ser cursado directamente por la comisión investigadora a lia 
Policía, o si tendría que verificarse por intermedio de un juez. Pareciera que la intervención de la autoridad judicial resultaría indispensable, pues nuestra Constitución dispone claramente en su art. $2^{\circ}$, inciso $20-\mathrm{g}$ ) que "nadie puede ser detenido sino por mandamiento escrito y motivado del juez o por las autoridades policiales en flagrante delito".

Puede suceder que una persona cumpla con comparecer ante la comisión, pero que se niegue a responder las preguntas o las evada sistemáticamente. Cabría obligarlo a responder o calificar su silencio como una aceptación de culpa o responsabilidad frente a los hechos que se le imputan en las preguntas? Evidentemente se trata de apremios judiciales propios de los procedimientos penales y civiles, pero hasta qué punto son aplicables a quien comparece ante una comisión investigadora?

En favor de una interpretación que rechace tal posibilidad, podría argumentarse que en el procedimiento investigatorio ante la comisión se carece de garant ías procesales fundamentales, como la presencia de un juez que vele por el respeto de la ley, y el concurso de la defensa por un abogado o la protección del Ministerio Público, para resguardar los derechos del compareciente. Del otro lado, también cabría sostener que como la Constitución dispone la atribución de la comisión para valerse de los apremios propios del proceso judicial, no cabe distinción alguna y todos éstos resultan plenamente aplicables, especialmente si con ello se logra alcanzar los objetivos de la investigación y evitar que se vea frustrada o seriamente entorpecida por las maniobras y argucias del compareciente. En verdad estamos ante un aspecto medular y delicado, que amerita ser analizado y resuelto, pero que excede los alcances de este trabajo.

Y qué decir del secuestro de documentos, correspondencia o papeles privados, y el allanamiento de domicilios o locales, atribuciones estas que han sido asumidas por comisiones investigadoras parlamentarias en otros países? Si nos atenemos a las normas constitucionales referidas a los derechos al secreto e inviolabilidad de los papeles privados, la correspondencia y el domicilio, éstos sólo podrían verse restringidos en virtud de un mandamiento judicial. por lo que la comisión investigadora carecería de potestades para realizar estas acciones y para cursar tales órdenes a la Policía. Pero 
podría hacerlo por intermedio de un juez? Nuevamente estamos ante un aspecto fundamental que debiera ser esclarecido urgentemente.

En definitiva, resulta muy positiva y necesaria la disposición constitucional que hace aplicables los apremios judiciales a los requerimientos de comparecencia que formulan las comisiones investigadoras parlamentarias; pero la amplitud de esta norma y las insuficiencias a nivel legislativo y reglamentario, pueden convertir en inoperantes tales atribuciones. Cierto es que en el Perú no cabría afirmar que dichas comisiones cumplen funciones investigativas de tipo jurisdiccional, por lo que la pretensión de extenderles todos los apremios judiciales podría aparecer como excesiva; pero tampoco es menos cierto que el objetivo de la norma constitucional y el fundamento de la indiscutible potestad investigativa del Parlamento, es que estas comisiones puedan cumplir cabalmente sus funciones de fiscalización y control, para lo cual tienen que contar con medios coercitivos eficaces y concretos. Todas estas interrogantes exigen pues una pronta solución.

3.3 Atribuciones de la comisión investigadora frente a procedimientos en tramite ante el Poder Judicial y el Fuero Militar

Se ha hecho frecuente, en ciertos medios judiciales y castrenses, sostener que cuando un caso o asunto viene siendo objeto de juzgamiento ante el Fuero Común o el Fuero Privativo Militar, las .comisiones investigadoras parlamentarias carecen de competencia para indagar o intervenir en el esclarecimiento de tales hechos. Dicha argumentación proviene de una equivocada interpretación del inciso $2^{\circ}$ del art. 233 de la Constitución que dispone:

"art. $233^{\circ}$ : Son garantias de la administración de justicia:

inc. $2^{\circ}$ : La independencia en su ejercicio. Ninguna autoridad puede avocarse causas pendientes ante el órgano jurisdiccional ni interferir el ejercicio de sus funciones. Tampoco puede dejar sin efecto resoluciones que han pasado en autoridad de cosa juzgada ni cortar procedimientos en trámite ni modificar sentencias ni retardar su ejecución. Esta disposición no afecta el derecho de gracia". 
No es exacto sostener que si una comisión investigadora requice la comparecencia de algunas personas o del suministro de información en torno a lechos que vienen siendo objeto de juzgamiento ante los tribunales. se configuren atutomitteimente situaciones contuarias a lat Constitucion por estarse "avocando" o "interfiriendo" en causas pendient es de resolución jlidicial".

El vocablo AVOCARSE significa "utraer o llamar a si algin juez o tribunal superior sin provocación o apelaciom, la causa que se está litigando y que debe litigarse ante otro inferior. Se dice asi también siempre que un superior llama a si un negocio sometido a examen y' decision de un inferior". En consecuencia, la prohibición de avocarse a una causa que está sometida a conocimiento de un juez, supone que nadie (ni siquiera un tribunal jerárquicamente superior y menos aún una autoridad ajena a la función judicial) puede asumir jurisdición de motu propio, invadiendo. suspendiendo o sustrayendo de la competencia del juez la jurisdicción sobre la causa que éste ejerce.

Cuando las comisiones investigadoras parlamentarias indagan o citan a comparecer sobre asuntos que simultáneamente se hallan en trámite ante los órganos judiciales, ello en ningún caso puede conllevar que se suspenda, paralice o sustraiga la jurisdicción y el proceso en curso ante la autoridad judicial. La actuación de la comisión investigadora no reemplaza ni sustituye al proceso judicial, pues su finalidad y competencia en nada implican administrar justicia, resolver conflictos o imponer sanciones aplicando la ley. Su tarea está destinada a obtener información, a efectos de esclarecer hechos de interés público y fiscalizar el comportamiento de altos funcionarios, para ulteriormente poder hacer efectivos contra éstos los procedimientos de responsabilidad politica, penal o constitucional a que hubiera eventualmente lugar. Por ello tampoco la actuación de la comisión investigadora supone necesariamente INTERFERENCIA O VIOLACION DE LA AUTONOMIA DE LA ADMINISTRACION DE JUSTICIA, pues en ningún caso la comisión puede paralizar el proceso judicial, revisar o modificar las sentencias, impedir su cumplimiento o investigar la conducta funcional de los jueces.

Mal puede entonces pretenderse convertir en dogma que la simple existencia de un proceso judicial donde se conoce de un 
asunto. impida nombrar o actuar a una comisión parlamentaria para investigar el caso. Tal argumentación ha sido categóricamente dejada de lado en países como Estados Unidos y Argentina, en donde las comisiones investigadoras han alcanzado especial desarrollo, y más recientemente en la experiencia peruana, con ocasión de las comisiones investigadoras de los casos SANITAS, SVIRES y ACCOMARCA. En vez de postular la incompetencia de la comisión para investigar aspectos que ya se hallan sujetos a conocimiento de los órganos jurisdiccionales, es correcto sostener que la comisión deberá cuidar, en su actuación concreta, de mantenerse dentro de los limites impuestos por la especial naturaleza y racionalidad de su elevada función, sin pretender interferir o suplantar lo que corresponde espec íficamente a la administración de justicia y a la autonom ia del Poder Judicial.

Podria tal vez alguien cuestionar el interés o fundamento de la comisión para solicitar información documentaria o comparecencia de personas en casos que ya vienen siendo objeto de trámite judicial, pues en dicho proceso se determinará definitivamente la responsabilidad que pueda existir y la pena que corresponda. Sin embargo, no debe olvidarse que de los hechos sujetos a juicio pueden desprenderse responsabilidades de altos funcionarios, cuya conducta es objeto de fiscalización por el Congreso. o derivarse resultados cuyo esclarecimiento es de interés público. Y para cumplir estas funciones el Parlamento, a través de sus comisiones investigadoras, requicre también obtener información exacta y completa sobre los hechos en cuestión y el estado de los procesos judiciales.

Mención aparte merece el comportamiento asumido por el Fuero Militar, a raíz del juzgamiento que ha efectuado o viene efectuando de personal militar o policial procesado por delitos contra los Derechos Humanos perpetrados a consecuencia del ejercicio de sus funciones. Sucede que reiteradamente dicho Fuero se ha resistido a suministrar información a las comisiones investigadoras sobre la situación, el estado y la naturaleza de dichos procesos judiciales, e inclusive - en ciertos casos- a facilitar la comparecencia de los procesados pese al requerimiento de la comisión, alegando que ello implicaría estarse avocando o interfiriendo en la función jurisdiccional que le corresponde. 
Además de reiterar lo dicho en cuanto al notorio error que conlleva esta interpretación del Fuero Militar sobre el art. 2330 inc. 20 de la Constitución, que alude a la prohibición impuesta a toda autoridad de avocarse o interferir en procesos sujetos a tramitación judicial, conviene tener presente que la propia Carta, en el inciso 30 del art. 2330 dispone que "...los juicios por responsabilidad de funcionarios públicos, delitos de prensa y los que se refieren a derechos fundamentales garantizados por la Constitución siempre son públicos". De modo que no sólo las comisiones investigadoras parlamentarias tienen pleno derecho a exigir y obtener información en torno a estos procesos seguidos ante la Justicia Militar (toda vez que se trata de delitos contra derechos fundamentales de la persona, cometidos en el ejercicio de sus funciones por personal que cumple funciones públicas) sino que tal derecho asiste también a la opinión pública. La necesaria reserva del proceso, tanto en el Código de Justicia Militar como en el Código Penal, subsiste únicamente hasta que concluya la etapa de la instrucción.

\section{REFLEXION FINAL}

Las comisiones investigadoras parlamentarias están llamadas a cumplir un rol fundamental en el proceso de afianzamiento de nuestra institucionalidad democrática y constitucional, debiendo servir como medio de freno y control a los posibles excesos del poder, y para físcalizar la actuación de los altos funcionarios públicos, de las autoridades y los particulares, evitando que con su conducta transgredan impunemente la Constitución y las leyes.

Los positivos avances que contiene la Constitución en materia de la competencia y atribuciones de las comisiones investigadoras parlamentarias, se ven seriamente limitados por la ausencia de leyes, normas reglamentarias y prácticas del propio Congreso, que resuelvan las interrogantes y controversias que impiden actualmente un mejor desarrollo y una labor más eficiente de estas comisiones. Ciertamente no se trata de convertirlas en peligrosos instrumentos de concentración de poderes y atributos, que luego puedan servir para cometer abusos en contra de otros órganos del Estado o de los ciudadanos. Pero tampoco de resignarse a que vayan a subsistir en la condición de simples entidades burocráti- 
cas, carentes de autoridad y potestades suficientes para efectivizar las tareas de investigación y fiscalización que le son inherentes, como elemento necesario en la construcción de una sociedad verdaderamente democrática. 